\title{
RANCANG BANGUN CHARGER BATERAI UNTUK KEBUTUHANAN UMKM
}

\author{
Riskha Mirandha Hamid ${ }^{1 *}$, Rizky $^{2}$, Mohamad Amin ${ }^{3}$, Ida Bagus D. ${ }^{4}$ \\ ${ }^{1 *}$ Mahasiswa Teknik Elektronika Politeknik Negeri Balikpapan \\ ${ }^{2}$ Mahasiswa Teknik Mesin Politeknik Negeri Balikpapan \\ ${ }^{3,4}$ Teknik Mesin Politeknik Negeri Balikpapan \\ *email : riskha_mirandhahamid@yahoo.co.id
}

\begin{abstract}
Proccess of Design and arrange the $12 \mathrm{~V}$ battery charger unit have done for need Micro, Small, Medium Enterprises in Balikpapan. The charging proccess use AC source $220 \mathrm{~V}$ that reduce become $15 \mathrm{~V}$ in the input. At the charger, the negative terminal of DC source is connect to negative plat or anode from battery and the positive terminal from source is connect to positive plat or catode frome battery. From the trial we get output voltage is $12.20 \mathrm{~V}$, and output ampere that range of 0.6-0.9 A. Also, the time longer for charge the battery is 490 minutes and this was tested with Specifick Grafity Test as $1.2 \mathrm{Kg} /$ and Quick Test at the good Condition.
\end{abstract}

Key words : Source DC, Oxidation Reduction Reaction, Cathode and Anode, Charging charger.

\begin{abstract}
Abstrak
Telah dilakukan proses perancangan dan pembuatan alat charger baterai $12 \mathrm{~V}$ untuk keperluan Usaha Mikro Kecil dan Menengah (UMKM) di Balikpapan. Dimana proses pengisian baterai (charge) menggunakan sumber tegangan AC $220 \mathrm{~V}$ yang diturunkan menjadi $15 \mathrm{~V}$ untuk inputnya. Pada alat charger, terminal negatif sumber DC terhubung ke plat negatif atau anoda dari baterai dan terminal positif dari sumber adalah terhubung ke plat positif atau katoda baterai. Dari percobaan diperoleh Tegangan keluaran (V out) $12.20 \mathrm{~V}$, Arus keluaran (I Out) 0.6 - 0.9 A. Adapun lama pengisian baterai adalah selama 490 menit dan diuji dengan Specifik Grafity Test sebesar 1,2 Kg/l serta Quick Test pada kondisi (good).
\end{abstract}

Kata kunci : Sumber DC, Reaksi Reduksi Oksidasi, Katoda dan Anoda, Pengisian baterai

\section{Pendahuluan}

Baterai telah menjadi bagian dari kehidupan modern. Jumlah produk yang mengandalkan baterai sebagai sumber daya saat ini sangat banyak. misalnya komputer, ponsel, alat pacu jantung, lampu penerangan pedagang kaki lima, kendaraan, yang menggunakan baterai sebagai sumber listrik. Perangkat tersebut menggunakan baterai yang biasanya dapat dilakukan pengengisian kembali. Dengan mggunakan baterai yang dapat diisi kembali kita memberi 2 keuntungan untuk lingkungan dan ekonomi ${ }^{[1]}$. Dengan cukup berkembangnya teknologi yang dapat membuat baterai diisi kembali dan pentingnya peranan baterai sebagai sumber listrik untuk penerangan.

Mengingat banyaknya Usaha Mikro Kecil dan Menengah (UMKM) yang membuka usaha pada malam hari yang mana mereka membutuhkan baterai sebagai sumber penghasil listrik untuk penerangan yang mana apabila baterai tersebut dipakai dalam durasi 8 jam maka Arus (I) didalam baterai 5 Ah $12 \mathrm{~V}$ akan berkurang dan lampu akan menjadi redup, sehingga mereka harus mengisi ulang (charging) di tempat lain dikarenakan hanya sedikit orang yang memilikinya karena harganya yang cukup mahal. Dikarenakan kebutuhan mereka untuk charging baterai untuk penerangan usaha itu sudah menjadi kebutuhan setiap seminggu melakukan charging baterai sebanyak 3 kali bahkan bias 4 kali dan setiap mencharging harus membayar 5 ribu rupiah untuk sekali charging, sedangkan jika di kali sebulan mereka menghabiskan 
sebanyak 20 ribu rupiah hanya untuk charging baterai mereka. Maka dari itu peneliti mencoba membuat rancang bangun alat cahrging baterai dengan harga yang terjangkau oleh UMKM tersebut.

\section{Teori Dasar}

Baterai adalah suatu proses kimia listrik, dimana pada saat pengisian energi listrik diubah menjadi kimia dan saat pengeluaran/discharge energi kimia diubah menjadi energi listrik $^{[2]}$. Baterai menghasilkan listrik melalui proses kimia. Baterai atau akkumulator adalah sebuah sel listrik dimana didalamnya berlangsung proses elektrokimia yang reversible (dapat berkebalikan ) dengan efisiensinya yang tinggi. Yang dimaksud dengan reaksi elektrokimia reversibel adalah didalam baterai dapat berlangsung proses pengubahan kimia menjadi tenaga listrik (proses pengosongan) dan sebaliknya dari tenaga listrik menjadi tenaga kimia (proses pengisian) dengan cara proses regenerasi dari elektroda-elektroda yang dipakai yaitu, dengan melewatkan arus listrik dalam arah polaritas yang berlawanan didalam sel. Baterai terdiri dari dua jenis yaitu, baterai primer dan baterai sekunder.

\subsection{Jenis - jenis baterai}

a. Baterai Asam

Baterai asam yang bahan elektrolitnya adalah larutan asam belerang (sulfuric acid = H2SO4). Didalam baterai asam, elektrodaelektrodanya terdiri dari plat-plat timah peroksida $\mathrm{PbO} 2$ sebagai anoda (kutub positif) dan timah murni $\mathrm{Pb}$ sebagai katoda (kutub negatif).

b. Baterai Alkali

Baterai alkali bahan elektrolitnya adalah larutan alkali yang terdiri dari :

1. Nickel iron alkaline battery $\mathrm{Ni}-\mathrm{Fe}$ Battery.

2. Nickel cadmium alkaline battery $\mathrm{Ni}$ Cd

Battery Pada umumnya yang paling banyak digunakan adalah baterai alkali admium (NiCd).

\subsection{Kapasitas Baterai}

Kapasitas baterai yaitu kemampuan baterai menyimpan daya listrik atau besarnya energi yang dapat disimpan dan dikeluarkan oleh baterai. Besarnya kapasitas, tergantung dari banyaknya bahan aktif pada plat positif maupun plat negatif yang bereaksi, dipengaruhi oleh jumlah plat tiap-tiap sel, ukuran, dan tebal plat, kualitas elektrolit serta umur baterai. Kapasitas energi suatu baterai dinyatakan dalam ampere jam (Ah), misalkan kapasitas baterai 100 Ah 12 volt artinya secara ideal arus yang dapat dikeluarkan sebesar 5 ampere selama 20 jam pemakaian. Besar kecilnya tegangan baterai ditentukan oleh banyak sedikitnya sel baterai yang ada di dalamnya. Sekalipun demikian, arus hanya akan mengalir bila ada konduktor dan beban yang dihubungkan ke baterai. Kapasitas baterai menunjukan kemampuan baterai untuk mengeluarkan arus (discharging) selama waktu tertentu. Pada saat baterai diisi (charging), terjadilah penimbunan muatan listrik. Jumlah maksimum muatan listrik yang dapat ditampung oleh baterai disebut kapasitas baterai dan dinyatakan dalam ampere jam (Ampere hour). Kapasitas baterai dapat dinyatakan dengan persamaan dibawah ini :

$\mathrm{N}(\mathrm{Ah})=\mathrm{I}($ ampere $) \times \mathrm{t}$ (hours) $\ldots \ldots \ldots 1^{[3]}$

Dimana :

$\mathrm{N}=$ kapasitas baterai aki

$\mathrm{I}=$ kuat arus (ampere)

$\mathrm{t}=$ waktu $(\mathrm{jam} / \mathrm{sekonD})$

\subsection{Fungsi Baterai}

Baterai berfungsi sebagai penyimpan dan suplai arus listrik ${ }^{[4]}$. Karena baterai sebagai penyimpan dan suplai arus listrik yang sangat baik dan mudah dalam penggunaan, maka baterai sangat banyak digunakan dalam kehidupan sehari-hari. 


\subsection{Konstruksi Baterai}

Komponen-komponen baterai yang didesain untuk kendaraan terdiri atas :
a. Kotak Baterai
b. Elektrolit Baterai
c. Sumbat Ventilasi
d. Plat Positif dan Plat Negatif
e. Separator
f. Lapisan Serat Gelas (Fiber Glass)
g. Sel Baterai

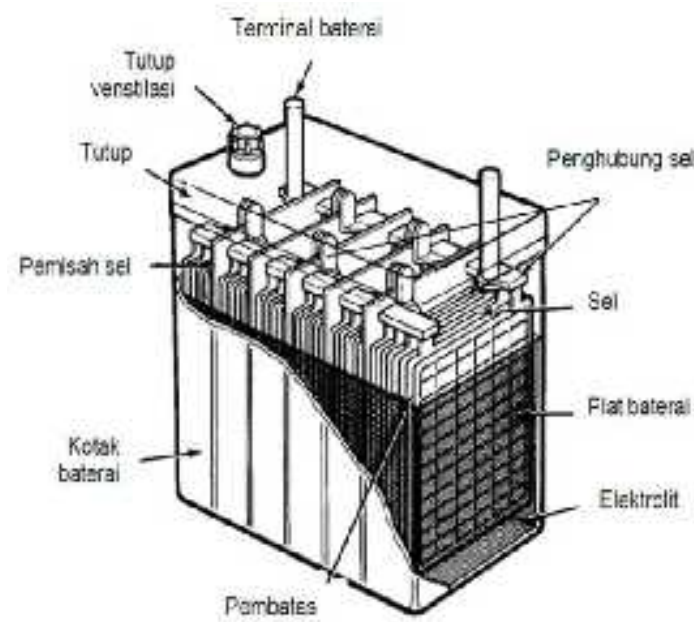

Gambar 1. Konstruksi Baterai ${ }^{[2]}$

\subsection{Prinsip kerja baterai}

Baterai merupakan perangkat yang mampu menghasilkan tegangan DC, yaitu dengan cara mengubah energi kimia yang terkandung didalamnya menjadi energi listrik melalui reaksi elektro kimia, Redoks (Reduksi-Oksidasi). Baterai terdiri dari beberapa sel listrik, sel listrik tersebut menjadi penyimpan energi listrik dalam bentuk energi kimia. Sel batere tersebut terdiri dari elektroda negatif dan elektroda positif. Elektroda negatif disebut katoda, yang berfungsi sebagai pemberi elektron. Elektroda positif disebut anoda yang berfungsi sebagai penerima elektron. Antara anoda dan katoda akan mengalir arus yaitu dari kutub positif (anoda) ke kutub negatif (katoda). Sedangkan electron akan mengalir dari katoda menuju anoda.

1. Proses pengosongan pada sel berlangsung menurut gambar. Jika sel dihubungkan dengan beban maka, elektron mengalir dari anoda melalui beban melalui beban katoda, kemudian ion - ion negatif mengalir ke anoda dan ion - ion positif mengalir ke katoda.

2. Pada proses pengisian menurut gambar dibawah ini adalah bila sel dihubungkan dengan power supply maka elektroda positif menjadi anoda dan elektroda negatif menjadi katoda dan proses kimia yang terjadi adalah sebagai berikut:

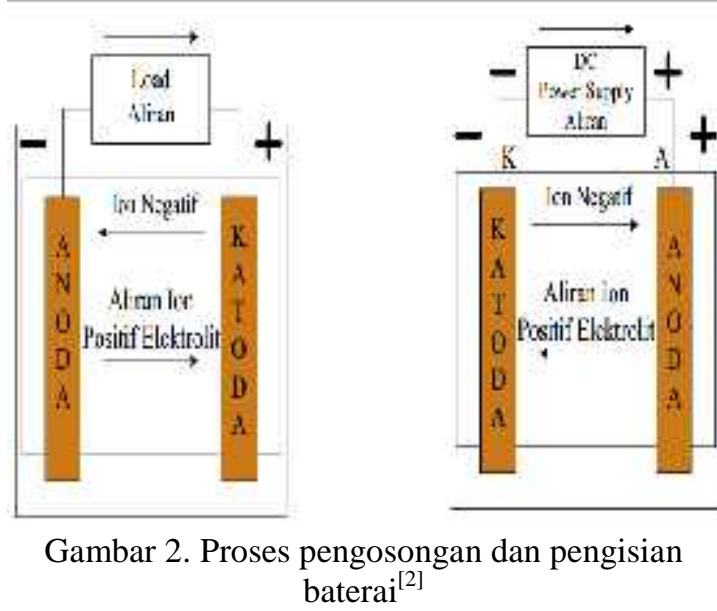

a. Aliran elektron menjadi terbalik, mengalir dari anoda melalui power supply ke katoda.

b. Ion-ion negatif mengalir dari katoda ke anoda.

c. Ion-ion positif mengalir dari anoda ke katoda Jadi, reaksi kimia pada saat pengisian (charging) adalah kebalikan dari saat pengosongan (discharging).

\subsection{Berdasarkan elektrolitnya}

Jenis baterai berdasarkan jenis elektrolitnya terdiri dari sel basah (baterai basah) dan sel kering (baterai kering). Baterai basah mempunyai ciri - ciri antara lain elektrolitnya berbentuk cair, kapasitas besar dan bentuk fisik besar. Sedangkan, baterai kering mempunyai ciri-ciri antara lain elektrolitnya berbentuk pasta, bentuk fisik umumnya lebih kecil dari baterai basah. 


\subsection{Charger}

Mengisi baterai disebut Charger. Pada saat proses pengisian batrai dengan meggunakan alat Charger Arus dialirkan berlawanan dengan waktu pengeluaran isi, pengisian berarti bahwa beban aktif dan elektrolit dirubah supaya energy kimia baterai mencapai maksimum ${ }^{[5]}$.

Pada saat proses pengisian Kapasitas rectifier harus disesuaikan dengan kapasitas baterai yang terpasanag, setidaknya kapasitas arusnya harus mencukupi untuk pengisian baterai sesuai jenisnya yaitu untuk baterai alkali adalah $0.2 \mathrm{C}(0.2 \mathrm{x}$ kapasitas $)$ ditambah beban statis (tetap) pada unit pembangkit.

Sebagai contoh jika suatu unit pembangkit dengan baterai jenis alkali kapasitas terpasangnya adalah 200Ah dan arus statisnya adalah 10 Ampere, maka Minimum Kapasitas Arus Rectifier (MKAR) adalah ${ }^{[2]}$ :

$$
\begin{aligned}
& \text { MKAR }=(0,2 \times 200 A h)+10 A h \\
& \text { MKAR }=40 A+10 A \\
& \text { MKAR }=50 \text { Ampere }
\end{aligned}
$$

Jadi kapasitas rectifier minimum yang harus disiapkan adalah sebesar 50 Ampere. Sumber tegangan AC untuk rectifier tidak boleh padam atau mati. Untuk itu pengecekan dilakukan baik tegangan masuk (AC) maupun tegangan keluarnya (DC).

\subsection{Jenis Charger}

Jenis Charger atau rectifier ada 2 (dua) macam sesuai sumber tegangannya yaitu rectifier 1 fasa dan rectifier 3 fasa.

1. Rectifier 1 fasa

Yang dimaksud dengan rectifier 1 fasa adalah rectifier yang rangkaian inputnya menggunakan AC suplai 1 fasa. Melalui MCB sumber AC suplai 1 fasa $220 \mathrm{~V}$ masuk ke dalam sisi primer trafo utama 1 fasa kemudian sisi sekunder trafo tersebut diubah menjadi tegangan DC $110 \mathrm{~V}$. Keluaran ini masih mengandung ripple cukup tinggi sehingga masih diperlukan rangkaian filter untuk memperkecil ripple tegangan output.

2. Rectifier 3 (tiga) fasa

Yang dimaksud dengan rectifier 3 fasa adalah rectifier yang rangkaian inputnya menggunakan AC suplai 3 fasa. Melalui MCB sumber AC suplai 3 fasa $380 \mathrm{~V}$ masuk ke dalam sisi primer trafo utama 3 fasa kemudian sisi sekunder trafo tersebut keluar tegangan AC $110 \mathrm{~V}$ per fasa kemudian melalui rangkaian penearah dengan diode bridge atau Thyristor bridge, arus AC tersebut diubah menjadi arus Dc $110 \mathrm{~V}$ yang masih mengandung ripple lebih rendah disbanding dengan ripple rectifier 1 fasa akan tetapi masih diperlukan rangkaian filter untuk lebih memperkecil ripple tegangan input.

\subsection{Prinsip Kerja Charger}

Sumber tegangan AC baik 1 fasa maupun 3 fasa yang masuk melalui terminal input trafo step-down dari tegangan $380 \mathrm{~V} / 220 \mathrm{~V}$ menjadi tegangan $110 \mathrm{~V}$ kemudian oleh diode penyearah/thyristor arus bolak-balik (AC) tersebut diubah menjadi arus searah dengan ripple atau gelombang DC tertentu.

Kemudian untuk memperbaiki ripple atau gelombang DC yang terjadi diperlukan suatu rangkaian penyaring (filter) yang dipasang sebelum terminal output.

\section{Metode penelitian}

Metode yang digunakan dalam penelitian ini adalah metode eksperimen. Adapun langkah-langkah yang diambil untuk melakukan penelitian ini meliputi Perancangan, persiapan bahan dan alat, perakitan alat, dan melakukan pengujian dengan satu baterai sampai terisi penuh

\subsection{Alat dan Bahan}

Alat dan Bahan yang dibutuhkan untuk penelitian eksperimen adalah sebagai berikut : 
a. 1 buah Steker

b. 1 buah trafo $3 \mathrm{~A}$

c. 2 buah Dioda

d. 3 buah resistor 100

e. 2 buah transistor : 1 buah TIP2955 dan

1 buah TIP3055

f. 1 buah IC regulator 7815

g. 4 buah kapasitor : 3 buah kapasitor $2200 \mu \mathrm{F}$ dan 1 buah kapasitor $3300 \mu \mathrm{F}$

h. LED

i. Sumber arus listrik tegangan 220 volt

\subsection{Desain Alat Charger $12 \mathrm{~V}$}

Alat charger ini diharapkan dapat memenuhi kebutuhan UMKM dengan harga terjangkau karena dibuat dari bahanbahan yang mudah didapatkan di toko elektronik di daerah Balikpapan. Adapun desain dan bentuk alat peraga tersebut dapat dilihat seperti pada gambar

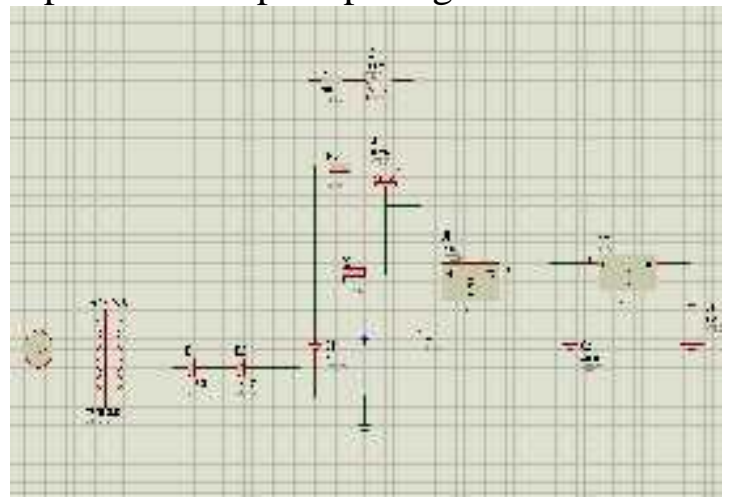

Gambar 3. Rancangan Alat charger

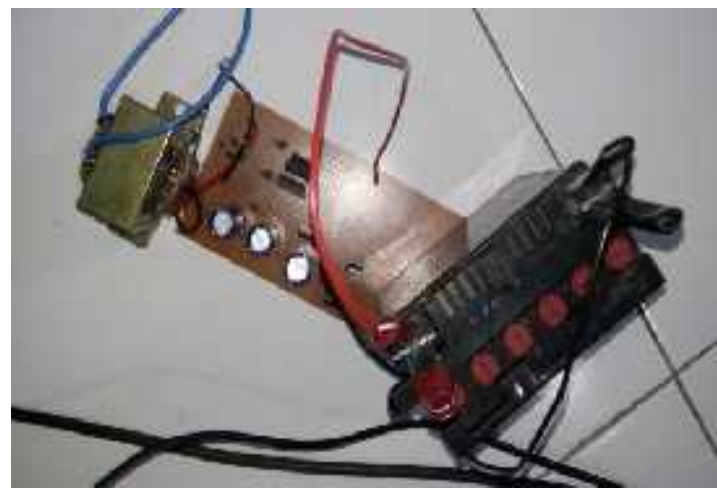

Gambar 4. Alat Charger 12 V (tampak atas)

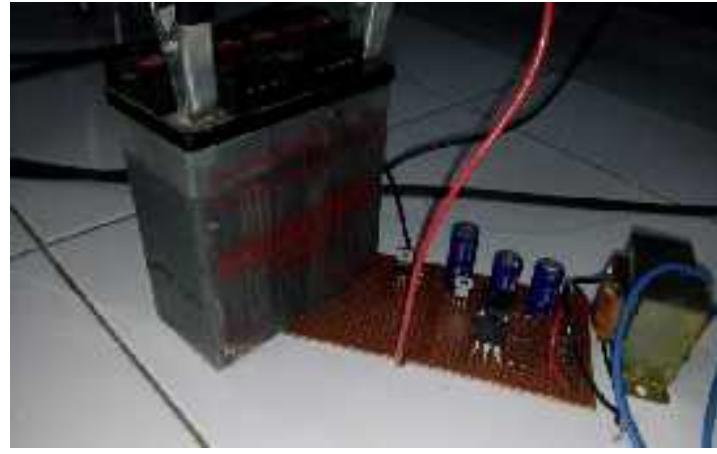

Gambar 5. Alat charger $12 \mathrm{~V}$ (tampak samping)

\subsection{Prinsip Kerja Alat}

Alat charger ini mendapatkan sumber arus listrik tegangan $220 \mathrm{~V}$ kemudian mengubah tegangannya menjadi $15 \mathrm{~V}$ dengan menggunakan trafo 0 dengan Arus 3 A. Kemudian arus dsearahkan menggunakan dioda, lalu arus melewati transistor dan $I C$ regulator 7815 sehingga keluarannya adalah tegangan $15 \mathrm{~V}$ dengan arus 0.6 sampai 0.9 A. selain itu ada kapasitor yang berperan dalam penyimpanan muatan sehingga proses charging baterai dapat berlangsung dengan aman.

\subsection{Pengujian Alat}

Adapun prosedur percobaan untuk alat charger $12 \mathrm{~V}$ adalah sebagai berikut :

1. Ukur berat jenis dari baterai, tegangan dan arus dalam baterai.

2. Sambungkan Output charger ke baterai $12 \mathrm{~V}$.

3. Sambungkan Alat ukur multimeter yang telah di seting pada selector $20 \mathrm{~V}$ pada output yang telah dihubungkan dengan baterai $12 \mathrm{~V}$.

4. Sambungkan Tang ampere pada output positif

5. Sambungkan input ke tegangan sumber $220 \mathrm{~V}$

6. Catat tegangan yang masuk ke baterai pada multimeter setiap 10 menit

7. Catat arus yang masuk ke baterai pada Tang Ampere setip 10 menit

8. Lakukan pemeriksaan suhu baterai setiap 10 menit dan catat hasilnya

9. Lakukan proses poin 6,7 , dan 8 sampai baterai terisi penuh $12 \mathrm{~V}$ 


\section{Data Hasil Penelitian}

Pengujian secara visual diperoleh data sebagai berikut :

Tegangan $(\mathrm{V})=11.24 \mathrm{~V}$

Arus $(\mathrm{I})=0.34 \mathrm{~A}$

Suhu $(\mathrm{T})=27.2^{\circ} \mathrm{C}$

Hydrometer $=1100($ Recharge $)$

Tabel 1. Hasil Pengujian Alat Charger

\begin{tabular}{|c|c|c|c|}
\hline $\begin{array}{c}\mathrm{t} \\
\text { (Menit) }\end{array}$ & $\begin{array}{c}\mathrm{I} \\
\text { (Ampere) }\end{array}$ & $\begin{array}{c}\mathrm{V} \\
\text { (Volt) }\end{array}$ & $\begin{array}{c}\mathrm{T} \\
\left({ }^{\mathrm{O}} \mathrm{C}\right)\end{array}$ \\
\hline 0 & 0.34 & 11.24 & 27.2 \\
\hline 10 & 0.60 & 11.57 & 27.3 \\
\hline 20 & 0.74 & 11.61 & 27 \\
\hline 30 & 0.72 & 11.63 & 27.1 \\
\hline 40 & 0.66 & 11.60 & 27.2 \\
\hline 50 & 0.70 & 11.67 & 27.3 \\
\hline 60 & 0.69 & 11.68 & 27. \\
\hline 70 & 0.68 & 11.70 & 27.7 \\
\hline 80 & 0.74 & 11.72 & 27.3 \\
\hline 90 & 0.74 & 11.73 & 27.2 \\
\hline 100 & 0.74 & 11.74 & 27.2 \\
\hline 110 & 0.70 & 11.75 & 26.9 \\
\hline 120 & 0.76 & 11.77 & 27.8 \\
\hline 130 & 0.77 & 11.80 & 28.6 \\
\hline 140 & 0.71 & 11.80 & 28.4 \\
\hline 150 & 0.7 & 11.80 & 28.5 \\
\hline 160 & 0.79 & 11.82 & 28.7 \\
\hline 170 & 0.81 & 11.83 & 28.8 \\
\hline 180 & 0.75 & 11.85 & 29.1 \\
\hline 190 & 0.77 & 11.86 & 29.2 \\
\hline 200 & 0.71 & 11.87 & 29.2 \\
\hline 210 & 0.76 & 11.89 & 28.5 \\
\hline 220 & 0.76 & 11.90 & 29.5 \\
\hline 230 & 0.84 & 11.91 & 29.6 \\
\hline 240 & 0.87 & 11.92 & 29.1 \\
\hline 250 & 0.80 & 11.93 & 28.9 \\
\hline 260 & 0.86 & 11.94 & 29.4 \\
\hline 270 & 0.85 & 11.96 & 29.5 \\
\hline 280 & 0.78 & 11.97 & 29.6 \\
\hline 290 & 0.89 & 11.98 & 29.6 \\
\hline 300 & 0.88 & 11.99 & 29.1 \\
\hline 310 & 0.87 & 12 & 28.4 \\
\hline 320 & 0.83 & 12.01 & 29.5 \\
\hline 330 & 0.88 & 12.02 & 28.8 \\
\hline 340 & 0.81 & 12.03 & 29 \\
\hline 350 & 0.84 & 12.04 & 29.2 \\
\hline 360 & 0.82 & 12.05 & 28.8 \\
\hline 370 & 0.83 & 12.06 & 29 \\
\hline 380 & 0.80 & 12.07 & 29 \\
\hline 390 & 0.84 & 12.07 & 29.1 \\
\hline 400 & 0.81 & 12.10 & 29.3 \\
\hline 410 & 0.83 & 12.11 & 29.1 \\
\hline 420 & 0.78 & 12.12 & 28.8 \\
\hline 430 & 0.83 & 12.13 & 28.8 \\
\hline 440 & 0.81 & 12.14 & 28.5 \\
\hline 450 & 0.81 & 12.15 & 18.7 \\
\hline 460 & 0.77 & 12.16 & 28.6 \\
\hline 470 & 0.84 & 12.17 & 29 \\
\hline 480 & 0.79 & 12.19 & 28.5 \\
\hline 490 & 0.86 & 12.20 & 28.8 \\
\hline
\end{tabular}

Dari penelitian yang dilakukan setelah diproleh data dapat dibuatkan grafik untuk pengaruh waktu terhadap arus, pengaruh waktu terhadap tegangan dan pengaruh waktu terhadap suhu sebagai berikut :

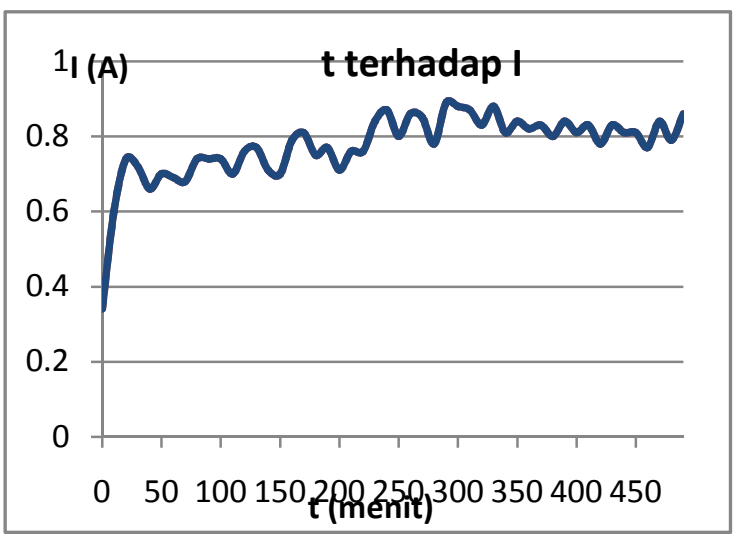

Gambar 6. Grafik Waktu (t) terhadap Arus (I)

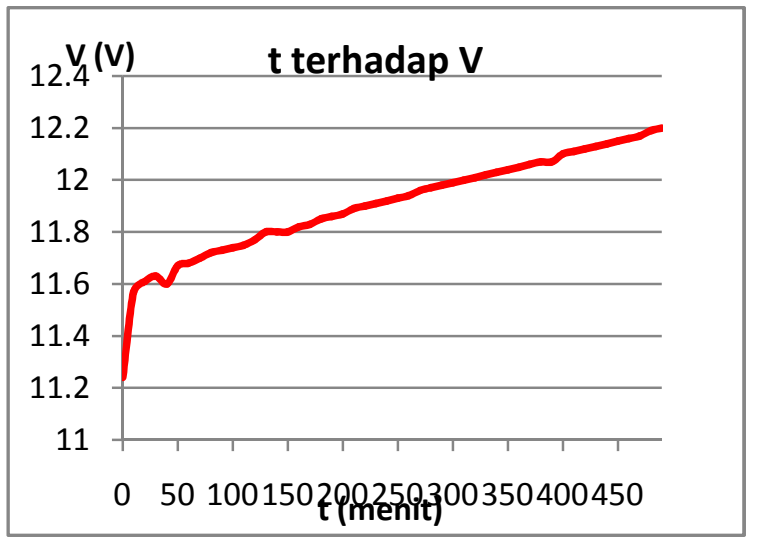

Gambar 7. Grafik Waktu (t) terhadap Tegangan (V)

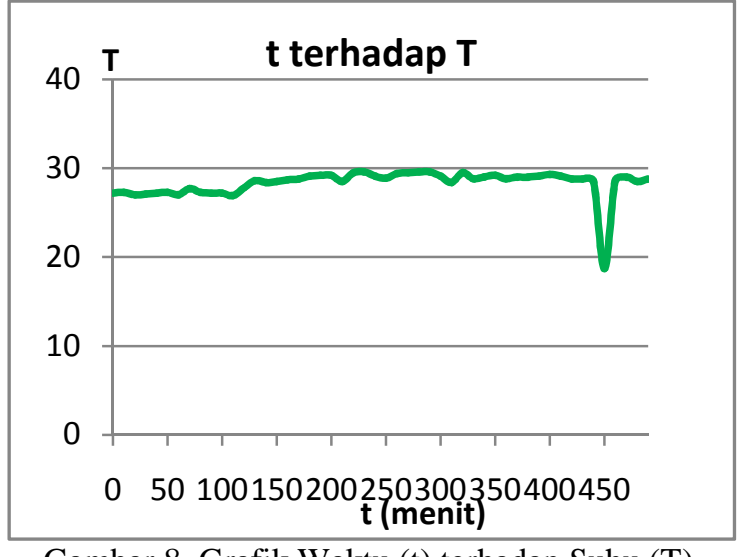

Gambar 8. Grafik Waktu (t) terhadap Suhu (T)

\section{b. Analisa}

Dari pengujian alat yang dilakukan didapatkan hasil uji alat yaitu, alat charger dapat mengisi baterai sampai penuh dari tegangan awal $11.24 \mathrm{~V}$ selama 8 jam. Dari table 1. dapat dilihat kenaikan tegangan 
setiap 10 menit adalah $\pm 0,02 \mathrm{~V}$. Serta terlihat arus yang masuk berkisar antara 0,6 A sampai dengan 0,88 A. Kemudian terjadi juga perubahan suhu baterai setiap 10 menit $\pm 0,1^{\circ} \mathrm{C}$

Lamanya waktu pengisian baterai ditentukan oleh kuatnya arus yang mengalir dari alat ke baterai. Berdasar rumus 2.1 untuk mencari lama waktu yang dibutuhkan untuk charging batrai 5 Ah adalah sebagai berikut :

$$
\begin{aligned}
& \mathrm{N} 5=\mathrm{IXt} \\
& 5 \mathrm{Ah}=0,88 \mathrm{Xt} \\
& \mathrm{t} \quad=5 \mathrm{Ah} / 0.6 \mathrm{~A} \\
& \mathrm{t} \quad=8,33 \mathrm{~h}
\end{aligned}
$$

Berdasarkan hasil perhitungan dan percobaan ekperimen pada alat waktu yang di butuhkan untuk charging batrei $5 \mathrm{Ah}$ selama 8, 33 Jam. Sehingga dapat dinyatakan alat ini layak untuk digunakan untuk kegiatan charging pada baterai yang digunakan kelompok UMKM.

\section{Kesimpulan}

1. Arus yang masuk ke batrai dengan Alat charger sebesar 0.6 A sampai dengan 0.88 A dengan tegangan input sebesar 15 Volt.

2. Waktu yang dibutuhkan untuk proses charging selama 8,33 jam.

\section{Saran}

Sebaiknya pada saat melakukan penelitian jaga keselamatan untuk diri praktikan, alat, dan bahan. Alat charging ini dapat digunakan oleh kelompok UMKM yang setiap 2 hari sekali melakukan charging baterai.

\section{Daftar Pustaka}

[1] Wonning,Paul. R, (2012), All About Rechargeable Batteries, Chargers and Recycling Home Guide Basic Series.

[2]Amin, Mohamad, (2016), Bahan Ajar Sistem Kelistrikan Alat Berat Politeknik Negeri Balikpapan, Balikpapan.
[3] http://www.bsierad.com/cara-pengisianbaterai-mobil-accuakil

[4]Daryanto, (1999), Teknik Pemeliharaan Mobil, Jakarta : Bumi Angkasa.

[5]Daryanto, (1999), Teknik Merawat Automobil Lengkap, Catakan Kelima, Bandung : Yrama Widya. 